\title{
Total Syntheses of Cystobactamids and Structural Confirmation of Cystobactamid 919-2
}

\author{
Bichu Cheng, * Rolf Müller, and Dirk Trauner*
}

\begin{abstract}
The cystobactamids are a family of antibacterial natural products with unprecedented chemical scaffolds that are active against both Gram-positive and Gram-negative pathogens. Herein, we describe the first total synthesis of cystobactamid 919-2 from three fragments. Our convergent synthesis enabled both the confirmation of the correct structure and the determination of the absolute configuration of cystobactamid 919-2.
\end{abstract}

$T_{\text {he development of antibiotics has been a milestone in the }}$ history of modern medicine. Many lifesaving drugs, such as the penicillins, the erythromycins, and vancomycin, were found during the "golden age" of antibiotics between 1940 and 1960. However, the discovery of new antibiotics has plummeted from the 1980s onwards. Most antibiotics approved for use in patients today are derived from a limited number of antibiotic types that had been established by the mid-1980s. ${ }^{[1]}$ The increase in multidrug resistance (MDR) and the low rate of new antibiotic development endanger public health, and put us at risk of returning to the pre-antimicrobial era. The development of new antibiotics faces a severe crisis in finding novel chemical scaffolds with activity against Gram-negative and multiresistant pathogens, in particular against the "ESKAPE" pathogens (Enterococcus faecium, Staphylococcus aureus, Klebsiella pneumoniae, Acinetobacter baumannii, Pseudomonas aeruginosa, and Enterobacter species). ${ }^{[2]}$

Natural products have historically been a valuable resource in the identification and development of antibacterial agents. ${ }^{[3]}$ The cystobactamids $(\mathbf{1}-\mathbf{3})$ are a novel class of antibacterial natural products recently isolated from Cystobacter $s p$. by Müller and co-workers. ${ }^{[4]}$ They are highly active against several Gram-positive pathogens, with cystobactamid 919-2 (2) being the most potent. More importantly, compound

[*] Dr. B. Cheng, Prof. Dr. D. Trauner

Department of Chemistry, University of Munich

Butenandtstrasse 5-13, Haus F, 81377 Munich (Germany) and

Department of Chemistry, New York University

100 Washington Square East, Room 712, New York, NY 10003 (USA)

E-mail: bc2548@nyu.edu dirktrauner@nyu.edu

Prof. Dr. R. Müller

Department of Microbial Natural Products

Helmholtz Institute for Pharmaceutical Research Saarland Helmholtz Center for Infection Research

Saarland University, 66123 Saarbrücken (Germany)

(2) Supporting information and the ORCID identification number(s) for

(D) the author(s) of this article can be found under:

https://doi.org/10.1002/anie.201705387. $\mathbf{2}$ also efficiently inhibits the growth of several Gram-negative pathogens, such as E. coli and A.baumannii. These compounds have been identified as inhibitors of bacterial type IIa topoisomerases, and the potency of $\mathbf{2}$ is comparable to or even exceeds that of ciprofloxacin, a fluoroquinolone antibiotic currently used in the clinic, thus offering exciting new alternatives for type II topoisomerase inhibitors. ${ }^{[5]}$

More recently, cystobactamid 919-2 was reisolated by Kim and co-workers from cultures of myxobacteria Corallococcus coralloides M23, together with coralmycins A (5) and B. ${ }^{[6]}$ Comparison of spectroscopic data of $\mathbf{2}$ with coralmycin A revealed ambiguities regarding the $\mathrm{NOE}$ correlations and optical rotation data (see below), which led to a revision of the relative stereochemistry of the $\beta$-methoxyasparagine moiety in cystobactamid 919-2 (4). With an additional hydroxy group on the benzoic acid unit, coralmycin A is even more potent against Gram-negative pathogens than cystobactamid 919-2 (Figure 1).

The isolation of cystobactamids from the natural producer is difficult, and yields are very low. For further development, compound supply must be sustained by an optimized biotechnological approach or scalable chemical synthesis. Both cystobactamids and coralmycins are nonribosomal peptides that consist of six unnatural amino acids, including one $\beta$-methoxyasparagine and five aromatic amino acids. ${ }^{[4]}$ The para-aminobenzoic acid (PABA) chain scaffold is unique, and has not been found before in natural products. ${ }^{[7]}$ Furthermore, both the nitro group ${ }^{[8]}$ and the isopropyl ether of the 3-hydroxy-4-aminobenzoic acid moieties ${ }^{[9]}$ are rare amongst natural products. Challenges associated with the synthesis of cystobactamids include the efficient synthesis of the monomeric PABA derivatives and their low reactivity in amide bond formation. Incorporation of the $\beta$-methoxyasparagine unit was also found to be nontrivial. Another unforeseen problem was the difficulty in separating the diastereomers at a late stage owing to their poor solubility and tendency to aggregate.

Herein, we describe the total syntheses of cystobactamids 507 (3) and 919-2. As the originally proposed structures of cystobactamid 919-1 (1) and 919-2 (2) are a pair of regioisomers, and the stereochemistry of the $\beta$-methoxyasparagine moiety was in dispute, we developed a divergent route that could lead to a range of cystobactamids. Retrosynthetically, we envisioned that Kim's revised structure of cystobactamid 919-2 (4) could be made from three fragments: activated ester $\mathbf{6}$, cyclic anhydride fragment $\mathbf{7}$, and aniline derivative $\mathbf{8}$ (Scheme 1).

The activated ester fragment $\mathbf{6}$ was prepared by esterification of the known acid $\mathbf{9}$ with pentafluorophenyl trifluoroacetate $\left(\mathrm{CF}_{3} \mathrm{CO}_{2} \mathrm{C}_{6} \mathrm{~F}_{5}\right) \cdot{ }^{[10]}$ The cyclic anhydride fragment 7 

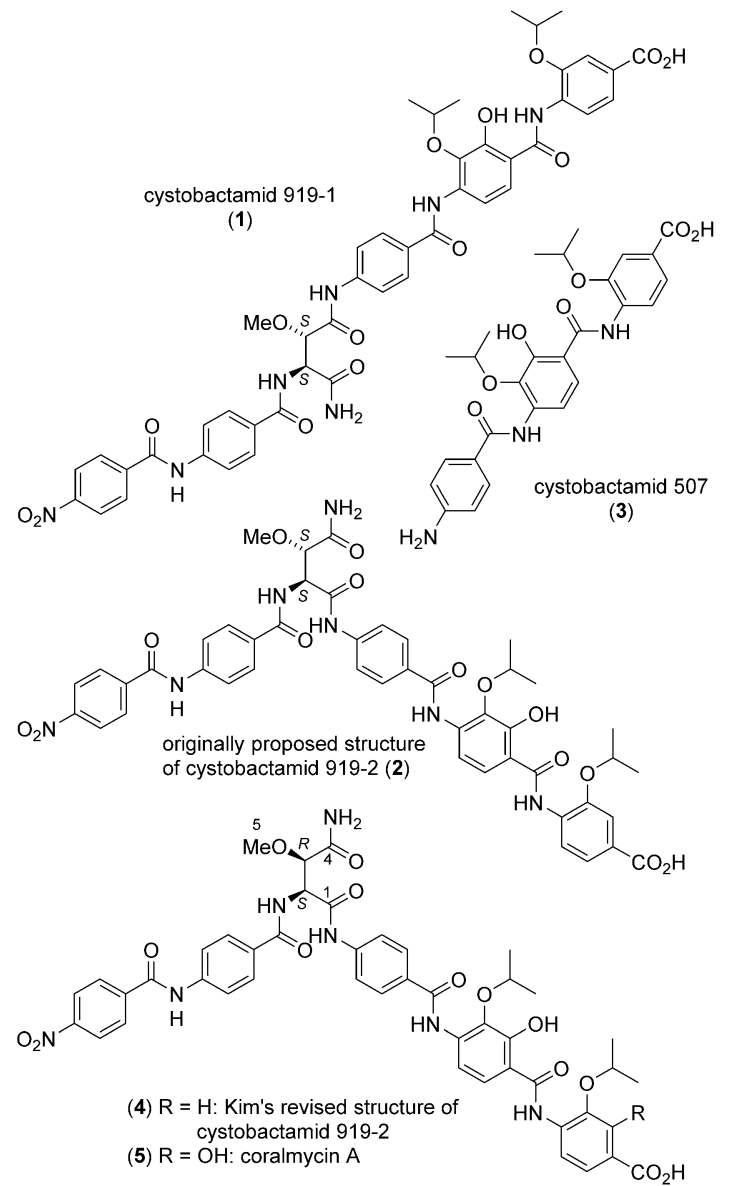

Figure 1. Structures of the cystobactamids and coralmycin A.

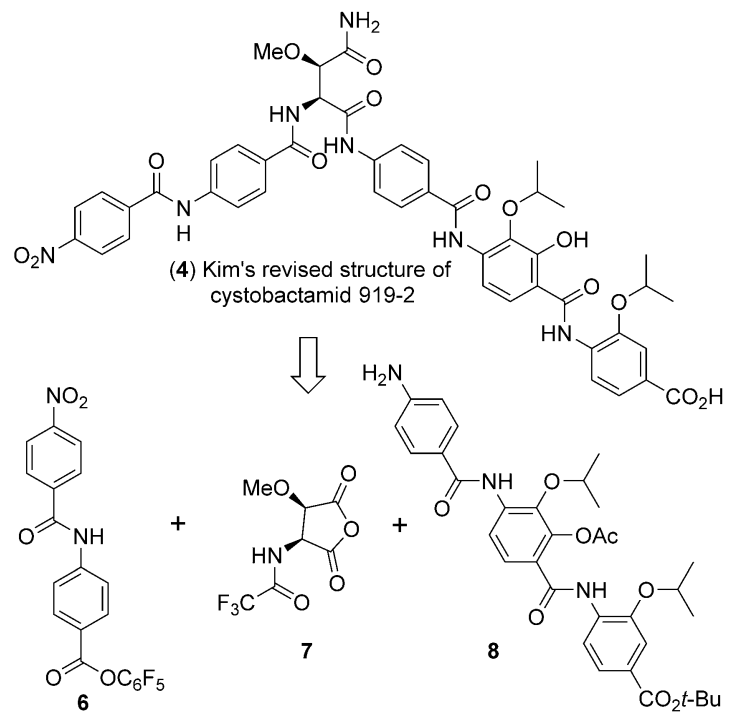

Scheme 1. Retrosynthetic analysis of Kim's revised structure of cystobactamid 919-92 (4).

was prepared from readily available L-diethyl tartrate (10). Compound $\mathbf{1 0}$ was transformed into the azido alcohol $\mathbf{1 1}$ in two steps following a literature procedure. ${ }^{[1]}$ Methylation of the alcohol under almost neutral conditions $\left(\mathrm{Ag}_{2} \mathrm{O} / \mathrm{MeI}\right)$ afforded the methyl ether product. Attempted hydrolysis of the ester under acidic or basic conditions led to partial epimerization. Alternatively, the azide group was first reduced by hydrogenation to the primary amine. Acidic hydrolysis of the diester afforded the corresponding dicarboxylic acid without epimerization. Finally, treatment of the acid with trifluoroacetic anhydride (TFAA) afforded the cyclic anhydride fragment $\mathbf{7}$ with concomitant protection of the amine as its trifluoroacetamide (Scheme 2). ${ }^{[12]}$

Regioselective alkylation of 2,3-dihydroxybenzaldehyde (12) with $2-\mathrm{PrBr}$ at the $3-\mathrm{OH}$ position ${ }^{[13]}$ and subsequent acetylation of the 2-OH group afforded the corresponding protected aldehyde (Scheme 3). Regioselective nitration ${ }^{[14]}$ followed by oxidation of the aldehyde with Oxone ${ }^{\circledR}$ gave the carboxylic acid $\mathbf{1 3} .^{[15]}$ The structure of $\mathbf{1 3}$ was confirmed by<smiles>O=C(Nc1ccc(C(=O)Nc2ccc(C(=O)OC(F)(F)F)cc2)cc1)c1ccc(NC(=O)c2ccc([N+](=O)[O-])cc2)cc1</smiles>

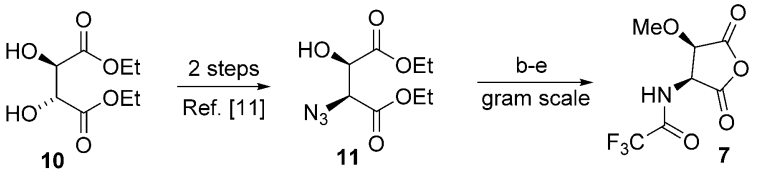

Scheme 2. Synthesis of activated ester 6 and cyclic anhydride 7. Reagents and conditions: a) $\mathrm{CF}_{3} \mathrm{CO}_{2} \mathrm{C}_{6} \mathrm{~F}_{5}$, pyridine, DMF (quant.); b) $\mathrm{Mel}, \mathrm{Ag}_{2} \mathrm{O}(99 \%)$; c) $\mathrm{Pd} / \mathrm{C}, \mathrm{H}_{2}(91 \%)$; d) $\mathrm{HCl}(6 \mathrm{M}), 100^{\circ} \mathrm{C}$; e) TFAA, RT (quant., 2 steps).<smiles>O=Cc1cccc(O)c1O</smiles>

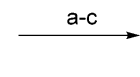<smiles>O=C(O)c1ccc([N+](=O)[O-])c(O)c1</smiles><smiles>C1CCCC1</smiles><smiles>CCCOC(=O)c1ccc2c(c1)OC(C)CN2</smiles><smiles>CCOC(=O)c1ccc(NC(=O)c2ccc(NC(=O)c3ccc(N)cc3)c(OC(C)C)c2OC(C)C)c(OC(C)C)c1</smiles>

cystobactamid 507 (3) $\mathrm{g}, \mathrm{h} \downarrow$

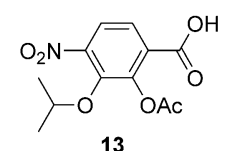<smiles>CC(C)Oc1cc(C(=O)OC(C)(C)C)ccc1NC(=O)c1ccc(N)c2c1OC(C)C(=O)O2</smiles>

16
Scheme 3. Synthesis of fragment 8 and cystobactamid 507 (3). Reagents and conditions: a) $\mathrm{NaH}, \mathrm{DMF} ; 2-\mathrm{PrBr} ; \mathrm{Ac}_{2} \mathrm{O}(34 \%)$; b) $\mathrm{NaNO}_{3}$, TFA, TFAA, DCM, -40 to $0^{\circ} \mathrm{C}$; c) Oxone ${ }^{\circledR}$, DMF $(71 \%$, 2 steps); d) $\mathrm{Boc}_{2} \mathrm{O}$, $t$ - $\mathrm{BuOH}$; piperidine; e) 2-Prl, $\mathrm{K}_{2} \mathrm{CO}_{3}$; f) $\mathrm{Pd} / \mathrm{C}, \mathrm{H}_{2}$ (69\%, 3 steps); g) $(\mathrm{COCl})_{2} ; \mathrm{NaHCO}_{3}$ (aq.); h) Pd/C, $\mathrm{H}_{2}(74 \%$, 2 steps); i) 4- $\mathrm{NO}_{2} \mathrm{C}_{6} \mathrm{H}_{4} \mathrm{COCl}$, 2,6-lutidine (91\%); j) $\mathrm{Pd} / \mathrm{C}, \mathrm{H}_{2},(91 \%)$; k) $\mathrm{HCl}$ (conc.); then $\mathrm{Na}_{2} \mathrm{CO}_{3}, \mathrm{CH}_{3} \mathrm{OH}(95 \%)$. 
X-ray crystallographic analysis of a single crystal (see the Supporting Information). The second fragment $\mathbf{1 5}$ was prepared from 3-hydroxy-4-nitrobenzoic acid (14). Esterification of $\mathbf{1 4}$ with $t$-BuOH,${ }^{[16]}$ alkylation of the phenol with 2-PrI, and reduction of the nitro group afforded aniline $\mathbf{1 5}$. Direct coupling of acid $\mathbf{1 3}$ and aniline $\mathbf{1 5}$ under standard amide coupling conditions worked poorly. Therefore, acid $\mathbf{1 3}$ was first transformed into the corresponding acid chloride, and further reaction with aniline $\mathbf{1 5}$ under Schotten-Baumann conditions afforded the amide product in good yield. Reduction of the nitro group by hydrogenation gave aniline 16. Amidation of $\mathbf{1 6}$ with 4-nitrobenzoyl chloride and another hydrogenation afforded the trimeric aniline fragment 8 . Removal of both the acetyl and the tert-butyl group afforded cystobactamid 507 (3). The spectroscopic data of synthetic $\mathbf{3}$ match those reported in the literature (Scheme 3)..$^{[4,17]}$

With ample amounts of fragments 6-8 in hand, we investigated the fragment coupling (Scheme 4). Reaction of aniline $\mathbf{8}$ with cyclic anhydride $\mathbf{7}$ in toluene cleanly afforded a 2.8:1 regioisomeric mixture of the ring-opened carboxylic acid products. ${ }^{[18]}$ The carboxylic acids from the ring-opening reaction were esterified with trimethyl orthoacetate to form the corresponding methyl esters $\mathbf{1 7}$ and $\mathbf{1 7}^{\prime} .{ }^{[19]}$ The major product $\mathbf{1 7}^{\prime}$ was separated from its regioisomer by flash column chromatography and was isolated in $69 \%$ yield. It was identified to be the $\beta$-isomer of the ring opening, as confirmed by X-ray analysis of a single crystal (Scheme 4 and the Supporting Information). ${ }^{[20]}$ Apparently, the additional methoxy group changed the regioselectivity, which usually favors the $\alpha$-isomer in similar reactions of aspartic anhydride with anilines. ${ }^{[12 a, 18]}$

Remarkably, aminolysis of either methyl ester $\mathbf{1 7}$ or $\mathbf{1 7}^{\prime}$ using aqueous $\mathrm{NH}_{3}$ in toluene afforded the same major product, primary amide $\mathbf{1 8}$, with concomitant removal of both the acetyl and trifluoroacetyl groups. We therefore concluded that the reaction occurred via aspartimide intermediate $\mathbf{1 9}$, a known complication in peptide synthesis. ${ }^{[21]}$ A $\beta$-selective ring opening of $\mathbf{1 9}$ with $\mathrm{NH}_{3}$ then afforded $\mathbf{1 8}$, the structure of which was elucidated by ${ }^{1} \mathrm{H}-{ }^{13} \mathrm{C}$ and ${ }^{1} \mathrm{H}-{ }^{15} \mathrm{~N}$ HMBC analysis of its acetate derivative $\mathbf{2 0}$ (see the Supporting Information, Figures S9-S13). The choice of organic cosolvent is critical for this reaction. The reaction became homogeneous in THF or $\mathrm{CH}_{3} \mathrm{OH}$, and significant amounts of side products were formed, while the reaction became heterogeneous in toluene, and the product precipitated from the solution. Only a small amount of side products was observed under these basic conditions. Separation of $\mathbf{1 8}$ from side products by flash column chromatography on silica gel was found to be difficult owing to their similar retention factors $\left(R_{\mathrm{f}}\right)$, poor solubility, and aggregation behavior on the column. ${ }^{[22]}$ It was found that

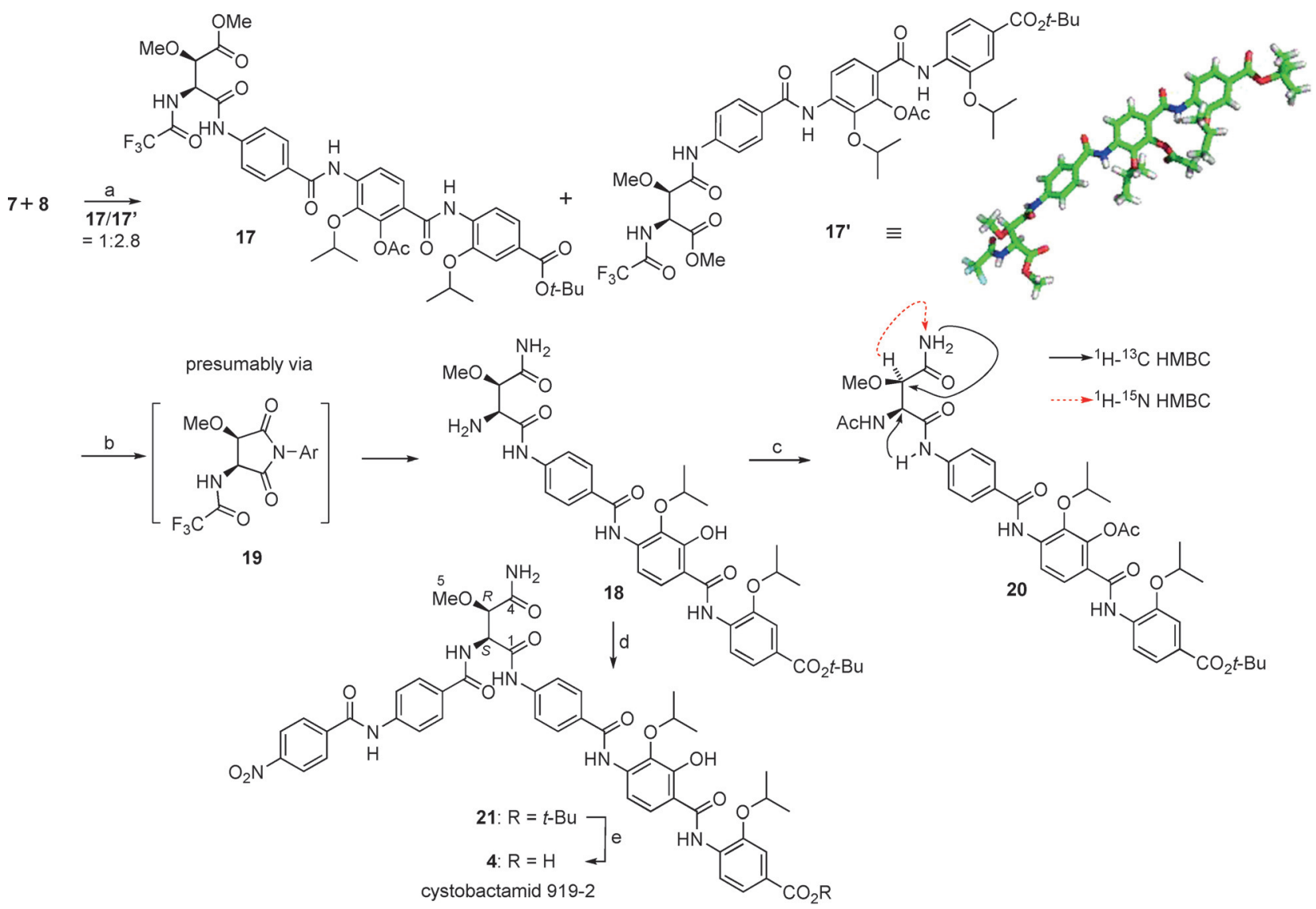

Scheme 4. Fragment coupling and synthesis of cystobactamid 919-2 (4). Reagents and conditions: a) toluene, $\mathrm{RT}$; then $\mathrm{MeC}(\mathrm{OMe}){ }_{3}, 80^{\circ} \mathrm{C}(69 \%$, yield of isolated $17^{\prime}$ ) ; b) $\mathrm{NH}_{3}$ (aq.), toluene, $0^{\circ} \mathrm{C}$ to $\mathrm{RT}\left(79 \%\right.$ from $17^{\prime}, 60 \%$ from 17 ); c) $\mathrm{Ac}_{2} \mathrm{O}$, pyridine (quant.); d) $6, \mathrm{~N}$-methylmorpholine, DMF $(83 \%)$; e) $\mathrm{TFA}, \mathrm{Et}_{3} \mathrm{SiH}(98 \%)$. 
trituration of the solid product mixture with hexanes/ethyl acetate (1:1) afforded analytically pure amine 18. Coupling of amine 18 with carboxylic acid 9 under amide coupling conditions (EDC, HOBT) did not afford a clean product owing to the influence of the free phenolic hydroxy group. However, coupling of $\mathbf{1 8}$ with the third fragment $\mathbf{6}$ occurred readily in DMF to give compound $\mathbf{2 1}$, and subsequent removal of the tert-butyl group with $\mathrm{TFA}^{[23]}$ afforded acid 4.

The spectroscopic data $\left({ }^{1} \mathrm{H}\right.$ and ${ }^{13} \mathrm{C}$ NMR; Figures S1-S3) of synthetic 4 fully match those of the natural cystobactamid 919-2 in both $\mathrm{CD}_{3} \mathrm{OD}$ and $\left[\mathrm{D}_{6}\right] \mathrm{DMSO}{ }^{[4,6]}$ The NMR data of the $\beta$-methoxyasparagine moiety are highly characteristic and listed in Table 1.

Table 1: Comparison of the ${ }^{1} \mathrm{H}$ and ${ }^{13} \mathrm{C}$ NMR spectroscopic data of the $\beta$ methoxyasparagine moieties in synthetic and natural cystobactamid 919-2, with coupling constants in Hertz given in parentheses.

\begin{tabular}{|c|c|c|c|c|c|c|}
\hline \multicolumn{2}{|c|}{ Position } & \multirow[t]{2}{*}{1} & 2 & 3 & \multirow[t]{2}{*}{4} & \multirow[b]{2}{*}{3495} \\
\hline \multirow{3}{*}{$\delta_{H}^{[a]}$} & synthetic & & $5.06, d(7.4)$ & $4.17, \mathrm{~d}(7.4)$ & & \\
\hline & Kim & & $5.06, d(8.0)$ & $4.18, d(8.0)$ & & $3.50, \mathrm{~s}$ \\
\hline & Müller & & $5.08, \mathrm{~d}(7.4)$ & $4.18, \mathrm{~d}(7.4)$ & & $3.50, \mathrm{~s}$ \\
\hline \multirow{3}{*}{$\delta_{H}{ }^{[b]}$} & synthetic & $\mathrm{NH} 8.49, \mathrm{~d}$ & $4.92, \mathrm{t}(8.1)$ & $4.10, \mathrm{~d}(8.0)$ & $\mathrm{NH}_{2} 7.49 / 7.58$ & $3.31, \mathrm{~s}$ \\
\hline & Kim & $\mathrm{NH} 8.46, \mathrm{~d}$ & $4.92, \mathrm{t}(8.0)$ & $4.09, \mathrm{~d}(8.0)$ & $\mathrm{NH}_{2} 7.47 / 7.54$ & $3.31, \mathrm{~s}$ \\
\hline & Müller & $\mathrm{NH} 8.46, \mathrm{~d}$ & $4.92, \mathrm{~m}$ & $4.09, \mathrm{~d}(7.9)$ & $\mathrm{NH}_{2} 7.48 / 7.55$ & $3.31, \mathrm{~s}$ \\
\hline \multirow{3}{*}{$\delta_{C}^{[b]}$} & synthetic & 168.74 & 55.77 & 79.97 & 170.92 & 57.75 \\
\hline & Kim & 168.6 & 55.7 & 79.7 & 170.8 & 57.7 \\
\hline & Müller & 168.4 & 55.4 & 79.8 & 170.6 & 57.4 \\
\hline
\end{tabular}

[a] In $\mathrm{CD}_{3} \mathrm{OD}$. [b] In $\left[\mathrm{D}_{6}\right] \mathrm{DMSO}$. For the positions, see Scheme 4.

For further confirmation, the NMR spectra $\left({ }^{1} \mathrm{H}\right.$ and $\left.2 \mathrm{D}\right)$ of a mixed sample of synthetic and natural cystobactamid 9192 were also measured, and they were analyzed by HPLC coinjection. Only one set of peaks was observed (Figures S4S6), thus confirming the identity of the natural product. Synthetic cystobactamid 919-2 (4) and the natural product exhibited very similar antibacterial activities against several bacterial strains (Table 2).

The CD spectrum also matched the reported one but surprisingly, the specific rotation $\left[+68^{\circ}\left(c=0.047, \mathrm{CH}_{3} \mathrm{OH}\right)\right.$; $+46^{\circ}\left(c=0.10, \mathrm{CH}_{2} \mathrm{Cl}_{2} / \mathrm{CH}_{3} \mathrm{OH} 1: 1\right) ;+24^{\circ}(c=0.33$, THF $\left.)\right]$ is of the opposite sign to the literature values $\left[-14.3^{\circ}(c=0.057\right.$, $\left.\left.\mathrm{CH}_{3} \mathrm{OH}\right) ;^{[4]}-14.4^{\circ}\left(c=0.08, \mathrm{CH}_{3} \mathrm{OH}\right)^{[6]}\right]$, which originally led the Müller group, in combination with NOE data, to assign

Table 2: Minimum inhibitory concentrations ( $\mathrm{MICs}$ in $\mu \mathrm{g} \mathrm{mL}^{-1}$ ) of natural and synthetic cystobactamid 919-2 and ciprofloxacin. ${ }^{[a]}$

\begin{tabular}{llll}
\hline Indicator strain & $\begin{array}{l}\text { Cys919-2 } \\
\text { (natural) }\end{array}$ & $\begin{array}{l}\text { Cys919-2 } \\
\text { (synthetic) }\end{array}$ & ciprofloxacin \\
\hline A. baumannii DSM-30008 & 4 & 4 & 0.5 \\
E. coli DSM-1116 & 4 & 8 & 0.013 \\
E. faecalis ATCC-29212 & 0.5 & 0.5 & 1.5 \\
S. aureus ATCC-29213 & 0.25 & 0.25 & 0.2 \\
\hline
\end{tabular}

[a] Determined as described in Ref. [4]. the stereochemical configuration as shown for $\mathbf{1}$ and $\mathbf{2}$. Kim and co-workers also observed discrepancies regarding the optical rotation data and concluded that the "determination of the absolute stereochemistry by optical rotation was difficult for cystobactamids". Even though cystobactamid 919-2 and coralmycin A have very similar spectroscopic data $\left({ }^{1} \mathrm{H},{ }^{13} \mathrm{C}\right.$ NMR and $\mathrm{CD}$ ) and proposed structures (see $\mathbf{4}$ and $\left.\mathbf{5}\right)$, opposite specific rotations were determined. ${ }^{[6]}$ A careful investigation of our measurement showed that owing to the low solubility of cystobactamid 919-2 (4), trace amounts of insoluble sample greatly influenced the optical rotation. A consistent positive value was obtained only after filtration of the solution. In addition, the advanced intermediates in our synthesis also have positive specific rotation values. Therefore, we propose that the absolute configuration $(2 S, 3 R)$ of cystobactamid 919-2 (4) is correct as assigned by Kim and co-workers, but that the specific rotation value should be revised. The CD spectrum and specific rotation (after filtration) of an authentic sample confirmed our proposal (Figure S7). Indeed, configurational analysis of cystobactamids is not trivial and requires thorough examination. Consequently, total synthesis was crucial to remove any possible doubts.

In summary, we have completed total syntheses of cystobactamid 507 (3) and cystobactamid 919-2 (4). Our synthesis unequivocally established both the correct structure and absolute configuration of cystobactamid 919-2. The convergent nature of our synthesis and scalable syntheses of each fragment will also enable the production of compounds for further biological studies. Syntheses of other isomeric natural products in this family and studies of their structure-activity relationships are in progress. Further "azologization" of these natural products for photopharmacological studies will also be investigated. ${ }^{[24]}$

\section{Acknowledgements}

This work was supported by the European Science Foundation (ERC Advanced Grant 268795 to D.T.) and the Deutsche Forschungsgemeinschaft (SFB 749). We thank Dr. Peter Mayer for the X-ray crystal-structure analysis, Dr. Chin Lin for assistance with ${ }^{1} \mathrm{H}-{ }^{15} \mathrm{~N}$ HMBC measurements, Dr. Stephan Hüttel for a natural sample of cystobactamid 919-2, Dr. Kirsten Harmrolfs for the NMR mixing experiments, Alexander Popoff for the optical rotation and CD spectra of the natural and mixed samples, Dr. Viktoria Schmitt for the bioassay, and Dr. Frits Kamp and Brigitte Nuscher for assistance in the measurement of circular dichroism spectra. We also thank Ben Williams for helpful discussions during the preparation of this manuscript.

\section{Conflict of interest}

The authors declare no conflict of interest. 
Keywords: absolute configuration - antibiotics - peptides . structure elucidation $\cdot$ total synthesis

How to cite: Angew. Chem. Int. Ed. 2017, 56, 12755-12759 Angew. Chem. 2017, 129, 12929-12933

[1] a) A Scientific Roadmap for Antibiotic Discovery. Pew Charitable Trusts (11 May 2016); b) E. D. Brown, G. D. Wright, Nature 2016, 529, 336-343.

[2] a) L. B. Rice, J. Infect. Dis. 2008, 197, 1079-1081; b) R. Tommasi, D. G. Brown, G. K. Walkup, J. I. Manchester, A. A. Miller, Nat. Rev. Drug Discovery 2015, 14, 529-542.

[3] a) M. G. Moloney, Trends Pharmacol. Sci. 2016, 37, 689-701; b) T. A. Wencewicz, Bioorg. Med. Chem. 2016, 24, 6227-6252.

[4] S. Baumann, J. Herrmann, R. Raju, H. Steinmetz, K. I. Mohr, S. Hüttel, K. Harmrolfs, M. Stadler, R. Müller, Angew. Chem. Int. Ed. 2014, 53, 14605-14609; Angew. Chem. 2014, 126, 14835 14839.

[5] C. Mayer, Y. L. Janin, Chem. Rev. 2014, 114, 2313 -2342.

[6] Y. J. Kim, H. J. Kim, G. W. Kim, K. Cho, S. Takahashi, H. Koshino, W. G. Kim, J. Nat. Prod. 2016, 79, 2223-2228.

[7] A closely related natural product is albicidin; see: $\mathrm{S}$. Cociancich, A. Pesic, D. Petras, S. Uhlmann, J. Kretz, V. Schubert, L. Vieweg, S. Duplan, M. Marguerettaz, J. Noëll, I. Pieretti, M. Hügelland, S. Kemper, A. Mainz, P. Rott, M. Royer, R. D. Süssmuth, Nat. Chem. Biol. 2015, 11, 195-197.

[8] R. Parry, S. Nishino, J. Spain, Nat. Prod. Rep. 2011, 28, 152-167.

[9] Y. Wang, B. Schnell, S. Baumann, R. Müller, T. P. Begley, J. Am. Chem. Soc. 2017, 139, 1742-1745.

[10] M. Green, J. Berman, Tetrahedron Lett. 1990, 31, 5851-5852.

[11] A. Breuning, R. Vicik, T. Schirmeister, Tetrahedron: Asymmetry 2003, 14, 3301-3312.

[12] a) F. Weygand, P. Klinke, I. Eigen, Chem. Ber. 1957, 90, 1896 1905; b) F. Buron, G. Deguest, L. Bischoff, C. Fruit, F. Marsais, Tetrahedron: Asymmetry 2007, 18, 1625-1627.
[13] a) A. R. van Doorn, M. Bos, S. Harkema, J. van Eerden, W. Verboom, D. N. Reinhoudt, J. Org. Chem. 1991, 56, 2371-2380; b) B. Morandi, B. Mariampillai, E. M. Carreira, Angew. Chem. Int. Ed. 2011, 50, 1101-1104; Angew. Chem. 2011, 123, $1133-$ 1136.

[14] A. L. Banka, J. Botyanszki, S. H. Dickerson, M. Duan, M. R. Leivers, R. B. Mcfadyen, C. B. Moore, A. M. Redman, J. B. Shotwell, V. Tai, M D. Tallant, J. Xue, Patent WO2012037108 A1, 2012.

[15] B. R. Travis, M. Sivakumar, G. O. Hollist, B. Borhan, Org. Lett. 2003, 5, $1031-1034$.

[16] K. Nakamura, T. Nakajima, T. Aoyama, S. Okitsu, M. Koyama, Tetrahedron 2014, 70, 8097-8107.

[17] M. Moreno, W. A. M. Elgaher, J. Herrmann, N. Schläger, M. M. Hamed, S. Baumann, R. Müller, R. W. Hartmann, A. Kirschning, Synlett 2015, 26, 1175-1178.

[18] X. Huang, X. Luo, Y. Roupioz, J. W. Keillor, J. Org. Chem. 1997, $62,8821-8825$

[19] J. I. Trujillo, A. S. Gopalan, Tetrahedron Lett. 1993, 34, 73557358.

[20] CCDC 1552502 and 1552503 (13 and 17') contain the supplementary crystallographic data for this paper. These data can be obtained free of charge from The Cambridge Crystallographic Data Centre.

[21] Side Reactions in Peptide Synthesis (Ed.: Y. Tang), Elsevier, Amsterdam, 2015, pp. 119-161.

[22] M. Paradís-Bas, J. Tulla-Puche, F. Albericio, Chem. Soc. Rev. 2016, 45, $631-654$

[23] A. Mehta, R. Jaouhari, T. J. Benson, K. T. Douglas, Tetrahedron Lett. 1992, 33, $5441-5444$.

[24] J. Broichhagen, J. A. Frank, D. Trauner, Acc. Chem. Res. 2015, 48, $1947-1960$.

Manuscript received: May 25, 2017

Accepted manuscript online: July 21, 2017

Version of record online: August 30, 2017 